\title{
Classification of aerosol properties derived from AERONET direct sun data
}

\author{
G. P. Gobbi ${ }^{1}$, Y. J. Kaufman ${ }^{2}$, I. Koren ${ }^{3}$, and T. F. Eck ${ }^{4, *}$ \\ ${ }^{1}$ Inst. Scienze dell' Atmosfera e del Clima, CNR, Rome, Italy \\ ${ }^{2}$ NASA/Goddard Space Flight Center, 613.2, Greenbelt MD 20771, USA \\ ${ }^{3}$ Dep. of Environ. Sciences Weizmann Institute, Rehovot 76100, Israel \\ ${ }^{4}$ GEST, University of Maryland, Baltimore, MD, USA \\ *also at: NASA/GSFC, 614.4, Greenbelt MD 20771, USA
}

Received: 25 July 2006 - Published in Atmos. Chem. Phys. Discuss.: 14 September 2006

Revised: 14 December 2006 - Accepted: 27 December 2006 - Published: 25 January 2007

\begin{abstract}
Aerosol spectral measurements by sunphotometers can be characterized by three independent pieces of information: 1) the optical thickness (AOT), a measure of the column aerosol concentration, 2) the optical thickness average spectral dependence, given by the Angstrom exponent $(\alpha)$, and 3) the spectral curvature of $\alpha(\delta \alpha)$. We propose a simple graphical method to visually convert $(\alpha, \delta \alpha)$ to the contribution of fine aerosol to the AOT and the size of the fine aerosols. This information can be used to track mixtures of pollution aerosol with dust, to distinguish aerosol growth from cloud contamination and to observe aerosol humidification. The graphical method is applied to the analysis of yearly records at 8 sites in 3 continents, characterized by different levels of pollution, biomass burning and mineral dust concentrations. Results depict the dominance of fine mode aerosols in driving the AOT at polluted sites. In stable meteorological conditions, we see an increase in the size of the fine aerosol as the pollution stagnates and increases in optical thickness. Coexistence of coarse and fine particles is evidenced at the polluted sites downwind of arid regions.
\end{abstract}

\section{Introduction}

The aerosol optical thickness at wavelength $\lambda\left(\operatorname{AOT}(\lambda) \equiv \tau_{\lambda}\right)$ is a standard parameter measured by sunphotometers like the ones operating in the AERONET (Holben et al., 1998, http://aeronet.gsfc.nasa.gov). $\tau_{\lambda}$ represents the extinction of radiation of wavelength $\lambda$ that results from the presence of atmospheric aerosols. The Angström exponent $\alpha$ represents

Correspondence to: G. P. Gobbi

(g.gobbi@isac.cnr.it) the slope of the wavelength dependence of the AOT in logarithmic coordinates (Angstrom, 1929):

$\alpha(\lambda 1, \lambda 2)=-\ln \left(\tau_{\lambda 2} / \tau_{\lambda 1}\right) / \ln (\lambda 2 / \lambda 1)$

In the solar spectrum, $\alpha$ is a good indicator of the size of the atmospheric particles determining the AOT: $\alpha>1$ are mainly determined by fine mode, submicron aerosols, while $\alpha<1$ are largely determined by coarse, supermicron particles (e.g., Kaufman et al., 1994). The Angstrom parameter is commonly employed in operational sunphotometry. However, $\alpha$ alone does not provide unambiguous information on the relative weight of coarse and fine modes in determining the AOT. Large fine mode particles can have the same $\alpha$ as mixtures of coarse mode and small fine mode ones. We shall demonstrate this with examples in the next section.

Several authors have discussed how the spectral variation of the Angstrom exponent can provide further information about the aerosol size distribution (King et al., 1978; Nakajima et al., 1986; Kaufman, 1993; Eck et al., 1999; O'Neill et al., 2001a, b, 2003; Schuster et al., 2006). Kaufman (1993) pointed-out that negative values of the difference $\delta \alpha=\alpha(440,613)-\alpha(440,1003)$ indicate the dominance of fine mode aerosols, while positive differences indicate the effect of two separate particle modes. Eck et al. (1999) have shown how in the wavelength range $380-870 \mathrm{~nm}, \alpha$ can increase by a factor of $2-5$ as wavelength increases for biomass burning and urban aerosols, while remaining constant or decreasing in the presence of mineral dust. O'Neill et al. (2001a) demonstrated that an Angström exponent-based separation of coarse from fine mode contribution to AOT is feasible in part because of the coarse mode AOT spectral variation being approximately neutral. Schuster et al. (2006) addressed the link between Angstrom exponent curvature and the ratio between fine and total aerosol volume.

Published by Copernicus GmbH on behalf of the European Geosciences Union. 


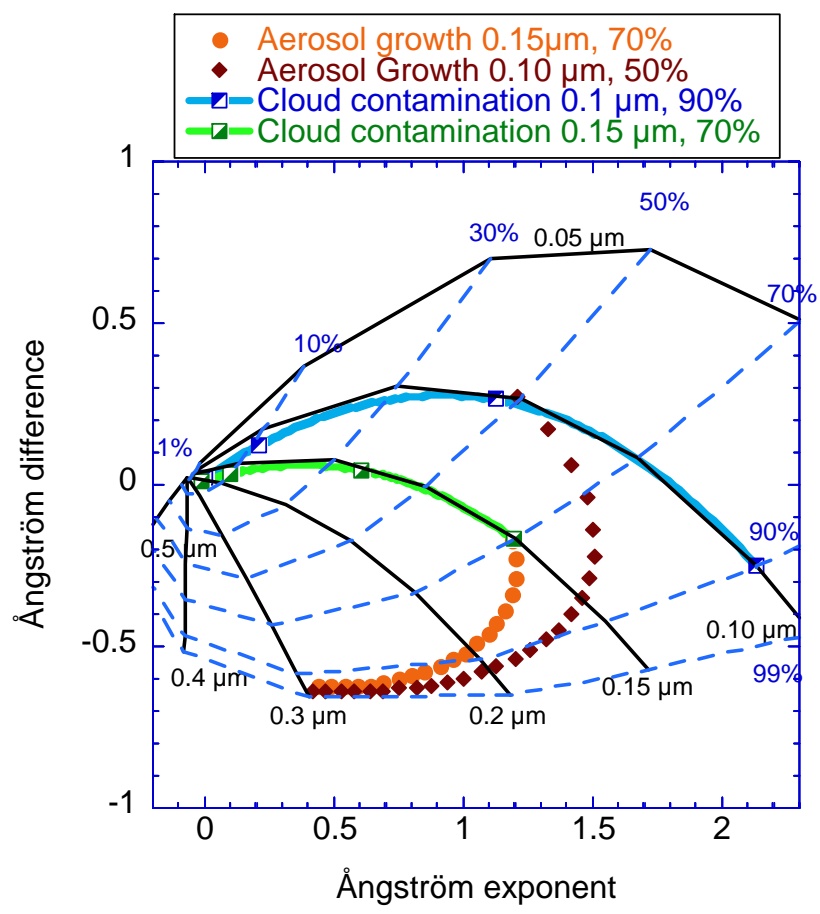

Fig. 1. Simulations of the classification of the aerosol properties as a function of the Angström exponent $\alpha(440,870)$ and the difference $\delta \alpha=\alpha(440,675)-\alpha(675,870)$, for bimodal, lognormal size distributions with refractive index $m=1.4-0.001 i$. The black solid lines are each for a fixed size of the fine mode $R_{f}$ and the dashed blue lines for a fixed fraction contribution $\eta$ of the fine mode to the AOT at $675 \mathrm{~nm}$. Split squares represent the effects of a cloud contamination of $0,50,90$ and $99 \%$ in the AOT of two grid points: 1) $\eta=70 \%, R_{f}=0.15$ (bright green line) and 2) $\eta=90 \%, R_{f}=0.1$ (turquoise line). This contamination results in a departure from the original grid points along the constant $R_{f}$ lines and towards the origin. Conversely, hydration of the aerosol fine mode (two starting conditions simulated: 1) $\eta=50 \%, R_{f}=0.1$ (brown diamonds), and 2) $\eta=70 \%, R_{f}=0.15$ (orange circles)) is accompanied by a movement towards the origin along the opposite direction, with concurrent increase in $R_{f}$ and $\eta$.

Here we build upon the concept of Kaufman (1993) to propose a new, straight-forward graphical framework that, on the basis of three spectral AOT observations, allows to: 1) infer aerosol fine mode size $\left(R_{f}\right)$ and fractional contribution to total AOT $(\eta)$, and 2) separate AOT increases due to aerosol humidification from AOT increases due to the addition of coarse particles as in the case of cloud contamination. To this end, we classify the aerosols in a new space, AOT vs. $\delta \alpha$ vs. $\alpha$. This space is invariant to the bulk AOT namely, the space is invariant to changes in AOT for a given size distribution. Any AOT will be in the same point if the fine and coarse modes stays the same. This space is sensitive to the balance between the fine and coarse modes and therefore is ideal to separate processes related to aerosol fine size from extinction fraction. Cloud contamination will enhance the weight of the coarse mode while humidification will increase the fine mode. Overall, this method provides an additional tool to interpret in terms of size-dependent properties, directsun observations of aerosol spectral extinction.

\section{Aerosol classification}

Unsupervised classification of aerosol using numerous measurements of the spectral optical thickness can supplement aerosol properties derived from less frequent multi-angle sky radiance inversions (e.g., Dubovik and King, 2000; Dubovik et al., 2002). We define the Angström exponent difference $\delta \alpha=\alpha(440,675)-\alpha(675,870)$ as a measure of the Angström exponent curvature $d \alpha / d \lambda$. Choice of the 440-870 nm wavelength range relies on the fact that these are highly accurate channels $\left(d \tau_{\lambda} \sim 0.01\right)$ of the AERONET sunphotometers (Eck et al., 1999; Holben et al., 1998) and these channels are available in all AERONET instruments. The $\delta \alpha$ vs. $\alpha(440,870)$ space (also addressed here as AdA coordinates) will be our framework for analyzing aerosol properties. In these coordinates, we further classify aerosols by representing their AOT by different colors. Since both $\alpha$ (440, 870) and $\delta \alpha$ are derived from $\tau_{\lambda}$, propagation of errors indicates the relevant indetermination to be $\Delta \alpha / \alpha \sim 2 \Delta \tau_{\lambda} / \tau_{\lambda}$ and $\Delta \delta \alpha / \delta \alpha \sim 5 \Delta \tau_{\lambda} / \tau_{\lambda}$, respectively. This converts to errors of $\geq 20 \%$ and $\geq 50 \%$ in $\alpha$ and $\delta \alpha$ for $\tau_{\lambda} \leq 0.10$. To avoid errors larger than $\sim 30 \%$, this work employs only observations of AOT $>0.15$.

The classification framework is explained with the help of Fig. 1. To interpret data in these coordinates, we determine reference points corresponding to bimodal size distributions characterized by a variety of fine mode $\left(R_{f}\right)$ and coarse mode $\left(R_{c}\right)$ modal radii combined to lead to prescribed fractions $(\eta)$ of the fine mode to total AOT (at $675 \mathrm{~nm}$ ). To this end, we performed Mie calculations of the aerosol spectral extinction for $R_{f}$ values of $0.05,0.1,0.15,0.2,0.3$ and $0.5 \mu \mathrm{m}$, for $R_{c}$ values of $0.75,1,2$, and $4 \mu \mathrm{m}$, and combined them to provide $\eta$ fractions of 1, 10, 30, 50, 70, 90 and $99 \%$. Each of the two modes (i) is assumed to have a log-normal size distribution:

$$
\begin{aligned}
& d N_{i} / d \ln r=\left[N_{c i} /\left((2 \pi)^{\frac{1}{2}} \ln \sigma_{i}\right)\right] \\
& \quad \exp \left[-\left(\ln r-\ln R_{i}\right)^{2} /\left(2 \ln ^{2} \sigma_{i}\right)\right]
\end{aligned}
$$

with fine and coarse mode widths $\sigma_{f}=1.5$ and $\sigma_{c}=1.8$, respectively. The range of size distribution parameters employed here is based on AERONET retrievals made at various sites both in aerosol source regions and downwind of sources (e.g., Dubovik et al., 2002), and therefore encompasses the expected range in particle size distribution dynamics. The $\delta \alpha$ and $\alpha$ values are then evaluated for each of these combinations and reported on the plot to make a reference grid. After verifying that $\delta \alpha$ values of the coarse modes do not vary significantly in the $440,870 \mathrm{~nm}$ range (e.g., O'Neill et al., 2001), the four $\delta \alpha, \alpha$ pairs (each pair corresponding to one of the four $R_{c}$ values) have been averaged to provide 
a single $\left(\eta, R_{f}\right)$ combination. Therefore, each $\left(\eta, R_{f}\right)$ grid point plotted in our figures represents the average of the relevant coarse modes results. Following the climatology of Dubovik et al. (2002), computations were made for refractive index typical of urban/industrial $(m=1.40-0.001 i)$ and mineral dust aerosols $(m=1.53-0.003 i)$, plus water droplets $(m=1.33-0.000 i)$.

Possible non-sphericity of particles is not expected to impact significantly on these results. Generally speaking, nonspherical aerosols introduce an AOT change smaller than $15 \%$ with respect to spherical ones (e.g., Mishchenko et al., 1997). In particular, supermicron non-spherical particles tend to generate similar extinction as spherical ones, with AOT differences between the three wavelengths (namely, 440,670 and $870 \mathrm{~nm}$ ) of less than $5 \%$, rapidly decreasing to $0 \%$ for increasing sizes.(e.g., Figs. 4, 5 and 6 in Mishchenko et al., 1997). Conversely, fine mode non-spherical particles are characterized by similar losses in extinction (with respect to spherical ones) at all the three wavelengths. (e.g., Figs. 4, 5 and 6 in Mishchenko et al., 1997), then leading to a minor impact on the Angstrom coefficients. On these basis, we expect this approach not to be significantly affected by the aerosol shape.

Grid points relevant to Mie calculations for $m=1.4-0.001 i$, plotted in the AdA coordinates (Fig. 1 and Table 1) show there is close to orthogonality of the aerosol fine size $R_{f}$ and extinction fraction $\eta$, i.e., we have good conditions for inference of these two parameters. Cloud contamination cases are computed by adding to the original size distributions a $10 \mu \mathrm{m}$ mode ( $m=1.33-0.0 i)$ generating 50,90 and $99 \%$ of the contaminated optical thickness, respectively. Figure 1 shows the effects of such contamination for two cases starting at: 1) $\eta=70 \%, R_{f}=0.15$ (bright green line) and 2) $\eta=90 \%, R_{f}=0.1$ (turquoise line), respectively. The three levels of contamination are represented by the split square symbols moving towards the origin along the colored, constant $R_{f}$ lines. That is, only a cloud contamination of the AOT larger than $90 \%$ will be located at $\alpha \sim \delta \alpha \sim 0$. Cloud contamination or increase in coarse aerosols have similar effects in the AdA coordinates. It is a goal of the cloud screening process (e.g, Kaufman et al., 2006) to exclude cloud-affected observations from the database in order to analyze aerosol data alone.

Aerosol hydration has been simulated by incremental growth of the fine mode $R_{f}\left(d R_{f}\right.$ steps $\left.=0.01 \mu \mathrm{m}\right)$ accompanied by dilution of the refractive index. In Fig. 1, two cases are shown to represent the patterns of hydration in the AdA coordinates for distributions with $m=1.4-0.001 i$ starting from, $\left(\eta=50 \%, R_{f}=0.1\right)$ and from $\left(\eta=70 \%, R_{f}=0.15\right)$, respectively. As expected, hydration leads to a growth in both $R_{f}$ and $\eta$. In the AdA coordinates this results in a movement in the opposite direction with respect to cloud contamination. This implies that even though aging and humidification of pollution aerosol and cloud contamination both decrease $\alpha$, they behave quite differently in the AdA coordinates, thus allowing for easy identification.

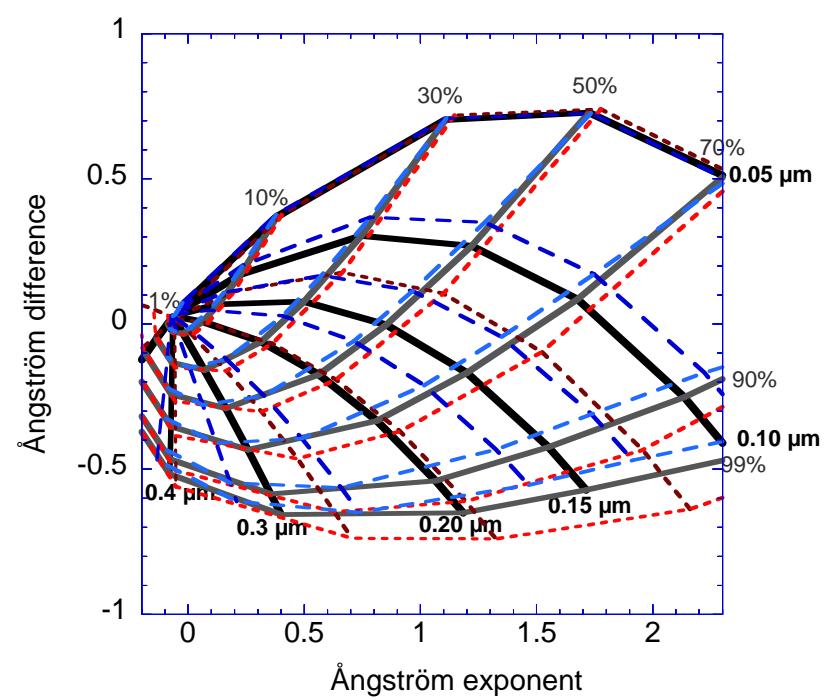

Fig. 2. Comparison of the $m=1.40-0.001 i$ grid (black/gray lines) with grids obtained for refractive indices $m=1.33-0.000 i$ (blue/pale-blue dashes), and $m=1.53-0.003 i$ (brown/red dashes).

Figure 2 illustrates the sensitivity of the classification scheme to refractive index. Computations indicate some clockwise rotation about the origin of the constant radius curves for increasing refractive index. The effect is much weaker in the case of the $\eta$ curves. For a given point $(\alpha, \delta \alpha)$ maximum $R_{f}$ indetermination is of the order of $\pm 25 \%$ for refractive index varying between $m=1.33-0.0 i$ and $m=1.53-$ $0.003 i$. At the same time, the fine mode extinction fraction, $\eta$ spans a range of the order of $\pm 10 \%$. Within this level of indetermination, the scheme is robust enough to provide an operational classification of the aerosol properties. Indeed, other grids can be computed by varying aerosol properties (e.g., modal radii and refractive index) or size distribution parameters. However, the simulations presented in Fig. 2 address most common aerosol typologies (e.g., Dubovik et al., 2002) and are intended to demonstrate the capability of this graphical approach at evaluating the climatology of aerosol size-related properties on the basis of standard photometric observations.

\section{Application to AERONET data}

The classification scheme is applied in Fig. 3 to one-year datasets from eight AERONET locations characterized by different aerosol types as pollution (P), mineral dust (D) and biomass burning (BB). The stations (and typical aerosol) are: Beijing, China (P, D), Rome, Italy (P, D), Kanpur, India (P, D), Ispra, Italy (P), Mexico City (P), GSFC, USA (P), Mongu, Zambia (BB) and Alta Floresta, Brasil (BB). All of these sites are either located in major aerosol source regions or downwind of source regions. These sites also have AOT that reach either moderate or high levels. Cloud 

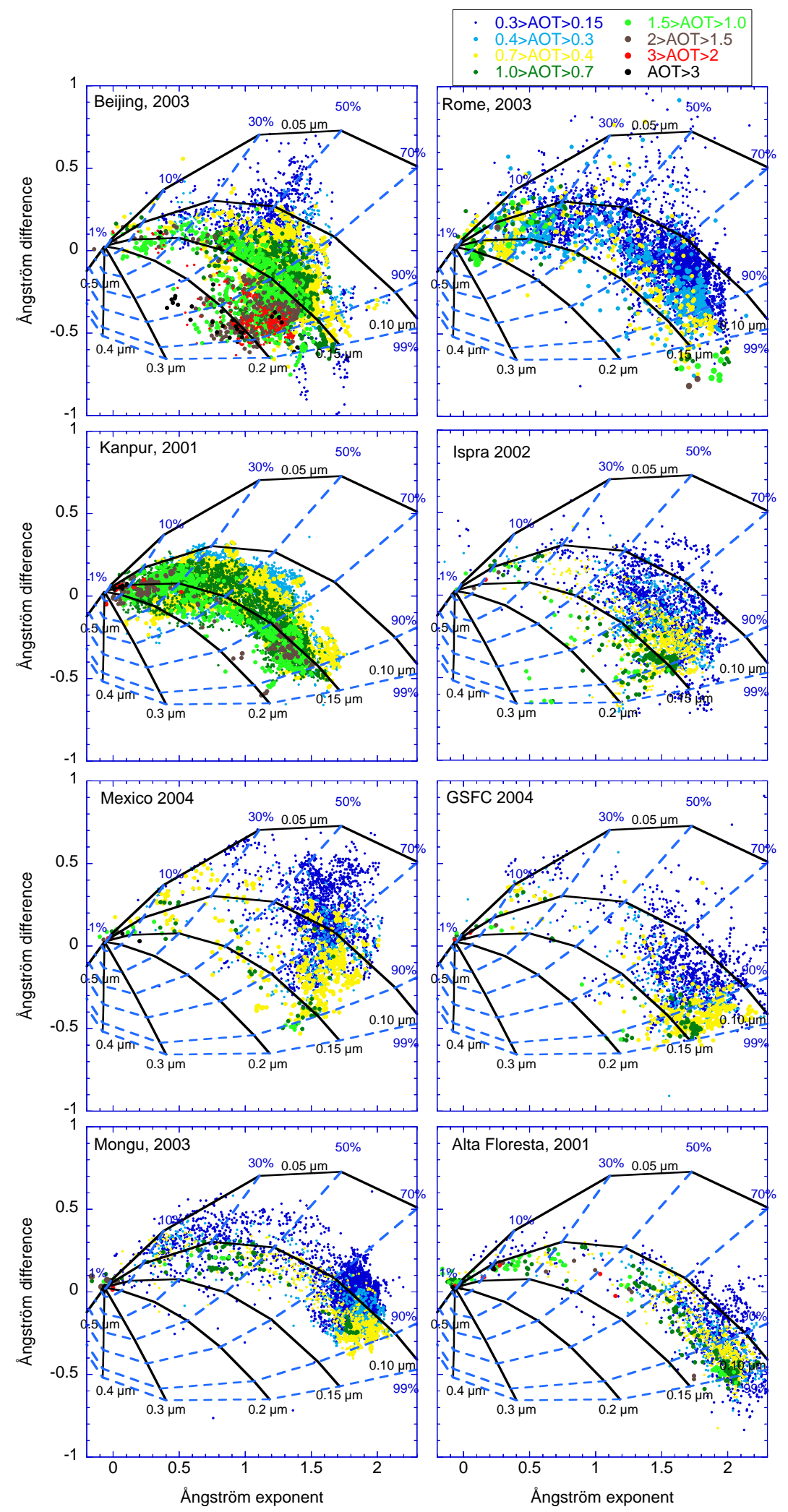

Fig. 3. Angstrom exponent difference, $\delta \alpha=\alpha(440,675)-\alpha(675,870)$, as a function of the $440-870 \mathrm{~nm}$ Angström exponent and AOT (color code) for eight AERONET stations (from top): Beijing (China), Rome (Italy), Kanpur (India), Ispra (Italy), Mexico City (Mexico), GSFC (USA), Mongu (Zambia) and Alta Floresta (Brasil). Only cloud-screened data with AOT $>0.15$ were used. 
Table 1. Computed $\alpha$ and $\delta \alpha$ grid points as a function of $R_{f}$ and $\eta$ values for refractive index $m=1.4-0.001 i$.

\begin{tabular}{|c|c|c|c|c|c|c|c|c|c|c|c|c|c|c|}
\hline$\eta$ & \multicolumn{2}{|c|}{$R_{f}=0.05 \mu \mathrm{m}$} & \multicolumn{2}{|c|}{$R_{f}=0.1 \mu \mathrm{m}$} & \multicolumn{2}{|c|}{$R_{f}=0.15 \mu \mathrm{m}$} & \multicolumn{2}{|c|}{$R_{f}=0.2 \mu \mathrm{m}$} & \multicolumn{2}{|c|}{$R_{f}=0.3 \mu \mathrm{m}$} & \multicolumn{2}{|c|}{$R_{f}=0.4 \mu \mathrm{m}$} & \multicolumn{2}{|c|}{$R_{f}=0.5 \mu \mathrm{m}$} \\
\hline $1 \%$ & 0.017 & 0.068 & 0.035 & 0.044 & 0.046 & 0.032 & -0.053 & 0.025 & -0.061 & 0.020 & -0.066 & 0.021 & -0.068 & 0.024 \\
\hline $30 \%$ & 1.108 & 0.703 & 0.746 & 0.304 & 0.499 & 0.077 & 0.314 & -0.061 & 0.069 & -0.158 & -0.069 & -0.133 & -0.135 & -0.051 \\
\hline $50 \%$ & 1.726 & 0.728 & 1.220 & 0.269 & 0.852 & -0.003 & 0.562 & -0.174 & 0.162 & -0.290 & -0.072 & -0.242 & -0.183 & -0.104 \\
\hline $70 \%$ & 2.306 & 0.509 & 1.676 & 0.085 & 1.199 & -0.168 & 0.812 & -0.333 & 0.257 & -0.433 & -0.074 & -0.353 & -0.232 & -0.160 \\
\hline
\end{tabular}

screening of this dataset has been applied according to Kaufman et al. (2006) for $\alpha>0.3$, and as AERONET level 1.5 for $\alpha<0.3$. To both provide a common reference and address the relative changes at each location (fine mode growth or coarse particle contamination) we employed the $m=1.4$ $0.001 i$ grid for all cases. The Beijing data show very high AOTs. ( $>2)$, mainly clustering in the fine mode growth wing $(\alpha<1.3, \delta \alpha<0)$. This wing is present at various levels also in Kanpur, Ispra, GSFC and Mexico City, locations characterized by rather heavy pollution but lower AOT than Beijing. High extinctions at these sites are then linked in many cases to a hygroscopic and/or coagulation growth from aging of the fine mode aerosols. At the same time coarse particles, likely mineral dust, superimpose their signal onto the pollution signature in Beijing and Kanpur.

For Beijing we have "typical pollution" with AOT $>0.7$ and $\alpha \sim 1.4$ (dark green concentration) that corresponds to a fine fraction of $\sim 75 \%$ and $R_{f} \sim 0.14 \mu \mathrm{m}$. As shown in Fig. 1, to take this aerosol and to contaminate it with clouds means to move along a line parallel to the black line of $0.15 \mu \mathrm{m}$, with an increasing apparent AOT. This is not what we see in Fig. 3. The extension of the Beijing pollution to higher AOTs happens perpendicularly to the black line, into larger size of the fine mode and fine fraction mainly between 70 and $90 \%$. Even in the presence of the coarse (likely dust) particles, AOT growth in many cases remains associated to fine mode growth. Such a coexistence of mineral dust and high pollution levels in Beijing is confirmed by the yearly particle analysis of Zheng et al. (2005). Similar conditions are also reported for Kanpur by Chinnam et al. (2006).

Alta Floresta, a site characterized by high biomass burning, provides a nice example of cloud contamination: the whole dataset shows a very coherent fine mode of 0.10 $0.13 \mu \mathrm{m}$ with concurrent increase in AOT and coarse mode fraction taking place exactly along the constant $R_{f}$ curves. In fact, both Alta Floresta and Mongu (the other biomassburning location) are sites with cloud contamination well hidden in the data, therefore difficult to remove even by wavelength dependent cloud screening (Kaufman et al., 2006). Overall, the two AdA plots of Mongu and Alta Floresta show smaller $R_{f}$ values at Mongu and also show greater $\delta \alpha$ values at Mongu that result in part from greater aerosol absorption (higher black carbon fraction) at this location (Eck et al., 2001).

In terms of coarse mode effects, Rome presents similarities with Beijing and Kanpur (e.g., Fig. 3). However, the fine mode is never observed to grow as in Beijing, and AOT mostly remains a factor of 2-4 times lower than in these two cities. The Rome AERONET station is located at the outskirts of the city, in a region where Saharan dust advection is recorded $\sim 20-30 \%$ of the time (Barnaba and Gobbi, 2004). Measurements clustering at higher Angstrom coefficients than in Beijing also denote a smaller size of the fine aerosols and less a persistent coarse mode. As expected from the MODIS observations (Barnaba and Gobbi, 2004), in spite of being only $400 \mathrm{~km}$ North of Rome, Ispra shows almost no sign of dust impact on its record. Conversely, fine mode growth is more evident at this site in part due to air stagnation in a mountain-surrounded valley (the Po valley is one of Europe's most polluted regions, e.g., Melin and Zibordi, 2005). In fact, high-pollution locations such as Ispra, Mexico City and GSFC have their measurements clustering in the $\alpha \sim 1.5, \delta \alpha \sim-0.5$ region, with growing AOT linked to both coagulation-aging and hydration-type increase in $R_{f}$. It is then reasonable to associate to aged pollution haze formation the branching of data along constant $\eta$ lines.

\section{Conclusions}

A graphical framework to classify aerosol properties using direct-sun sunphotometer observations has been presented. The method relies on the combined analysis of the Angstrom exponent $\alpha$ and of its spectral curvature $d \alpha / d \lambda$ here represented by $\delta \alpha=\alpha(440,675)-\alpha(675,870)$. Plotting data in these coordinates was shown to allow for inference of aerosol fine mode size and fractional contribution to total AOT. Adding information on AOT to the plot then permits to separate AOT growth by aerosol humidification and/or coagulation (aging) from AOT growth by inclusion of coarse mode particles or cloud contamination. Application to AERONET climatological data from three continents allowed to iden- 
tify various aerosol properties peculiar to these locations. Data from Beijing (China) and Kanpur (India) confirmed these locations to be affected by superposition of dust, and high pollution conditions. At both sites it is pollution haze (fine mode aerosols) that generates the largest aerosol loads, reaching AOT levels $>2$ in Beijing. The method allowed for easy identification of the mineral dust fingerprint in the Rome (Italy) data, while confirming the absence of a significant contribution of dust at the Ispra site, located just $400 \mathrm{~km}$ North. Growing haze appears in this framework as a branching along higher fine mode radius and extinction fraction. Conversely, locations where biomass burning represents the main source of aerosols showed limited hygroscopic growth of fine mode particles, and a rather focused range of fine mode size $\left(d R_{f} \sim 0.05 \mu \mathrm{m}\right)$. In these cases, some cloud contamination was observed at the two sites of Alta Floresta (Brazil) and Mongu (Zambia). Overall, the analysis scheme provides an additional, versatile tool to characterize aerosol properties and to explore the important aerosol-cloud border region by means of easily accessible, direct sun photometric observations.

Acknowledgements. This work was initiated while Yoram Kaufman was visiting ISAC Rome in the Autumn of 2005. Yoram passed away on May 31, 2006. Here we wish to acknowledge Yoram's intuition, curiosity, generosity and creative energy. This paper in large part is the fruit of his many talents. Special thanks to the AERONET groups who kindly provided their data. Part of this research was supported by the EU ACCENT Network. I.K. is incumbent of the Benjamin H. Swig and Jack D. Weiler career development.

Edited by: T. Wagner

\section{References}

Angstrom, A.: On the atmospheric transmission of sun radiation and on dust in the air, Geogr. Ann., 11, 156-166, 1929.

Barnaba, F. and Gobbi, G. P.: Aerosol seasonal variability over the Mediterranean region and relative impact of maritime, continental and Saharan dust particles over the basin from MODIS data in the year 2001, Atmos. Chem. Phys., 4, 2367-2391, 2004, http://www.atmos-chem-phys.net/4/2367/2004/.

Chinnam, N., Dey, S., Tripathi, S. N., and Sharma, M.: Dust events in Kanpur, northern India: Chemical evidence for source and implications to radiative forcing, Geophys. Res. Lett., 33, L08803, doi:10.1029/2005GL025278, 2006.

Dubovik, O. and King, M. D.: A flexible inversion algorithm for retrieval of aerosol optical properties from Sun and sky radiance measurements, J. Geophys. Res., 105, 20 673-20 696, 2000.

Dubovik, O., Holben, B. N., Eck, T. F., Smirnov, A., Kaufman, Y. J., King, M. D., Tanre, D., and Slutsker, I.: Variability of absorption and optical properties of key aerosol types observed in worldwide locations, J. Atmos. Sci., 59, 590-608, 2002.
Eck, T. F., Holben, B. N., Reid, J. S., Dubovik, O., Smirnov, A., O'Neill, N. T., Slutsker, I., and Kinne, S.: Wavelength dependence of the optical depth of biomass burning, urban, and desert dust aerosols, J. Geophys. Res., 104, 31 333-31 349, 1999.

Eck, T. F., Holben, B. N., Ward, D. E., Dubovik, O., Reid, J. S., Smirnov, A., Mukelabai, M. M., Hsu, N. C., O’Neill, N. T., and Slutsker, I.: Characterization of the optical properties of biomass burning aerosols in Zambia during the 1997 ZIBBEE field campaign, J. Geophys. Res., 106, 3425-3448, 2001.

Holben, B. N., Eck, T. F., Slutsker, I., Tanre, D., Buis, J. P., Setzer, A., Vermote, E., Reagan, J. A., Kaufman, Y. J., Nakajima, T., Lavenu, F., Jankowiak, I., and Smirnov, A.: AERONET - A federated instrument network and data archive for aerosol characterization, Rem. Sens. Environ., 66, 1-16, 1998.

Kaufman, Y. J.: Aerosol optical thickness and atmospheric path radiance, J. Geophys. Res., 98(D2), 2677-2692, 1993.

Kaufman, Y. J., Gobbi, G. P., and Koren, I.: Aerosol climatology using a tunable spectral variability cloud screening of AERONET data, Geophys. Res. Lett., 33, L07817, doi:10.1029/2005GL025478, 2006.

King, M. D., Byrne, D. M., Herman, B. M.: Aerosol size distribution obtained by inversion of spectral optical depth measurements, J. Atmos. Sci., 35, 2153-2167, 1978.

Mélin F. and Zibordi, G.: Aerosol variability in the Po Valley analyzed from automated optical measurements, Geophys. Res. Lett., 32, L03810, doi:10.1029/2004GL021787, 2005.

Mishchenko, M. I, Travis, L. D., Kahn, R. A., and West, R. A.: Modeling Phase Functions for dustlike tropospheric aerosols using a shape mixture of randomly oriented polydisperse spheroids, J. Geophys. Res., 102(D14), 16831-16847, 1997.

Nakajima, T., Takamura, T., Yamano, M.: Consistency of aerosol size distributions inferred from measurements of solar radiation and aerosols, J. Met. Soc. Jap., 64, 765-776, 1986.

Nakajima, T. and King, M. D.: Determination of the optical thickness and effective particle radius of clouds from reflected solar radiation measurements. Part I: Theory, J. Atmos. Sci., 47, 187818931990.

O’Neill, N. T., Dubovik, O., and Eck, T. F.: A modified Angstrom coefficient for the characterization of sub-micron aerosols, Appl. Opt., 40, 2368-2375, 2001a.

O’Neill, N. T., Eck, T. F., Holben, B. N., Smirnov, A., and Dubovick, O.: Bimodal size distribution influences on the variation of Angstrom derivatives in spectral and optical depth space, J. Geophys. Res., 106(D9), 9787-9806, 2001 b.

O’Neill, N. T., Eck, T. F., Smirnov, A., Holben, B. N., and Thulasiraman, S.: Spectral discrimination of coarse and fine mode optical depth, J. Geophys. Res., 108(D17), 4559, doi:10.1029/2002JD002975, 2003.

O’Neill, N. T., Thulasiraman, S., Eck, T. F., and Reid, J.S.: Robust optical features of fine mode size distributions: Application to the Quebec smoke event of 2002, J. Geophys. Res., 110, D11207, doi:10.1029/2004JD005157, 2005.

Schuster, G. L., Dubovick, O., and Holben, B. N.: Angstrom exponent and bimodal aerosol size distributions, J. Geophys. Res., 111, D07207, doi:10.1029/2005/JD006328, 2006.

Zheng, M., Salmon, L. G., Schauer, J. J., Zeng, L., Kiang, C. S., Zhang, Y., and Cass, G. R.: Seasonal trends in PM2.5 source contributions in Beijing, China, Atmos. Env., 39, 3967-3976, 2005. 